Article

\title{
Synthesis, Spectroscopic Properties and Antipathogenic Activity of New Thiourea Derivatives
}

\section{Carmen Limban ${ }^{1}$, Luminita Marutescu ${ }^{2}$ and Mariana Carmen Chifiriuc ${ }^{2,3, *}$}

1 Pharmaceutical Chemistry Department, University of Medicine and Pharmacy Carol Davila, Bucharest, Romania; E-Mail: carmen_limban@yahoo.com

2 Microbiology Department, Faculty of Biology, University of Bucharest, Ale. Portocalelor 1-4, Bucharest 60101, Romania; E-Mail: lumi_dascalu@yahoo.com

3 National Institute for Research and Development in Microbiology and Immunology "Cantacuzino", Spl. Independentei 103, Bucharest 060031, Romania

* Author to whom correspondence should be addressed; E-Mail: carmen_balotescu@yahoo.com.

Received: 4 August 2011; in revised form: 29 August 2011 / Accepted: 1 September 2011 /

Published: 6 September 2011

\begin{abstract}
A number of acylthioureas, 2-((4-methylphenoxy)methyl)- $N$-(arylcarbamothioyl)benzamides (aryl = 3,5-dichlorophenyl, 2,3-dichlorophenyl, 3,4-dichlorophenyl, 2,4,5-trichlorophenyl, 3,4,5-trichlorophenyl, 2-bromophenyl, 2,4-dibromophenyl, 2,5-dibromophenyl, 2-iodophenyl, 3-fluorophenyl, 2,3,4-trifluorophenyl, 2,4,5-trifluorophenyl, 2,4,6-trifluorophenyl) have been synthesized, characterized by elemental analysis, IR and NMR spectroscopy and tested for their interaction with bacterial cells in free and adherent state. The anti-pathogenic activity was correlated with the presence of one iodine, bromide or fluorine, and two or three chloride atoms on the N-phenyl substituent of the thiourea moiety, being significant especially on Pseudomonas aeruginosa and Staphylococcus aureus strains, known for their ability to grow in biofilms. Our results demonstrate the potential of these derivatives for further development of novel antimicrobial agents with antibiofilm properties.
\end{abstract}

Keywords: acylthioureas; benzamides; 2-(4-methylphenoxymethyl)benzoic acid; antimicrobial activity; bacterial biofilm 


\section{Introduction}

Nowadays antibiotic resistance has become a serious public health problem. As a result of the rapid development of resistance to the existing portfolio of antimicrobial drugs, there is an increasing need to design new antibacterial and antifungal agents with better activity profiles and lower toxicity.

In recent years, thiourea derivatives have become a subject of interest due to their antibacterial, antifungal, antimycobacterial and antileprotic activities. A thiourea system attached to a polycyclic imide, such as thiourea derivatives of 4-azatricyclo[5.2.2.0 $\left.0^{2,6}\right]$ undec-8-ene-3,5-dione, showed significant inhibitory activity against Gram-positive cocci [1]. Some pyridazine derivatives carrying thiourea moieties exhibit potent inhibitory activity against Staphylococcus aureus, Escherichia coli, Candida albicans and C. parapsilosis [2]. 1-Aroyl-3-arylthioureas showed moderate to potent activity against different bacterial strains, especially against $E$. coli strains resistant to standard drugs [3]. The antibacterial activity of the 1-aroyl-3-(substituted-2-benzothiazolyl)thioureas makes these substances promising agents for the treatment of infections. [4]. $N^{1}, N^{2}$-disubstituted thioureas, such as $N$-phenyland $N$-benzoylthioureas, have also attracted attention due to their potential application in medicinal chemistry as antimicrobial agents [5].

Novel aroyl, thiophenoyl, morpholinoyl and butanoyl thiourea derivatives containing a thiazole moiety, such as $N$-[(1,3-thiazol-2-ylamino)carbonothioyl]thiophene-2-carboxamide and $N$-[(1,3thiazol-2-ylamino)carbonothioyl]morpholine-4-carboxamide exhibit broad spectrum antifungal activity [6]. For example, the 1-(isomeric fluorobenzoyl)-3-(isomeric fluorophenyl)thioureas were proven to exhibit better antifungal than antibacterial activity, probably due to the inclusion of fluorine that may increase the lipophilicity and enhance the rate of cell penetration and transport of the drug to an active site. The higher polarizability due to the $\mathrm{C}-\mathrm{F}$ bond may provide new possibilities for binding to the receptor [7].

$N$-phenyl- $N^{\prime}$-[4-(5-cyclohexylamino-1,3,4-thiadiazole-2-yl)phenyl]thiourea is active against Mycobacterium tuberculosis $\mathrm{H}_{37} \mathrm{Rv}$ [8]. In an effort to improve the therapeutic value of thiocarlide, several $N$-pentofuranosyl- $N^{\prime \prime}$-[p-isoamyloxy)phenyl]thioureas were tested as potential anti-tuberculosis therapeutic agents. $N$-D-Aldopentofuranosyl- $N^{\prime}$-[p-(isoamyloxy)phenyl]thiourea derivatives, designed as structural analogues of thiocarlide, have recently been reported to be more potent than thiocarlide itself [9]. Novel 1-(5-cyclobutyl-1,3-oxazol-2-yl)-3(sub)phenyl/ pyridyl thiourea compounds inhibited Mycobacterium tuberculosis $\mathrm{H}_{37} \mathrm{Rv}$ and a clinical isolate of multidrug- resistant M. tuberculosis [10].

Many articles have presented the progress in the investigation of new thiourea derivatives as anthelmintics [11], antimalarials [12], antitumor agents [13], analgesics [14] and antivirals [15,16], these compounds proving also useful as insecticides [17,18], fungicides [19], herbicides [20], and plant-growth regulators [21]. Metals complexes with $\mathrm{N}$-acyl thiourea ligands have been described in the literature with regard to their synthesis, general characterization and biological activity, such as cancerostatic activity [22].

Taking into account the improvement of the antimicrobial activity by the inclusion of fluorine in the organic molecule of thioureas [7], we synthesized, characterized and studied the antimicrobial activity of the new 2-((4-methylphenoxy)methyl)- $N$-(arylcarbamothioyl)benzamides, substituted with phenyl groups carrying one, two or three atoms of $\mathrm{F}, \mathrm{Cl}, \mathrm{Br}$ and $\mathrm{I}$. 


\section{Results and Discussion}

\subsection{Chemistry}

Our decision to synthesize and evaluate this kind of substances for their antimicrobial activity was influenced by several reports disclosing the antimicrobial activities of thiourea-based compounds. We have previously synthesized and demonstrated the microbicidal activities of 2-(4-methoxyphenoxymethyl)benzoic acid [23], 2-(4-chlorophenoxymethyl)benzoic acid [24], 2-(4-fluorophenoxymethyl)benzoic acid [25], 2-(4-ethylphenoxymethyl)benzoic acid [26,27], and 2-(4-methylphenoxymethyl)benzoic acid thioureides [28].

Scheme 1. Synthesis of the new compounds.<smiles>O=C1OCc2ccccc21</smiles>

5<smiles>Cc1ccc(O)cc1CO</smiles>

$\mathrm{KOH}$<smiles>Cc1ccc(OCc2ccccc2C(=O)[OH2+])cc1</smiles>

6

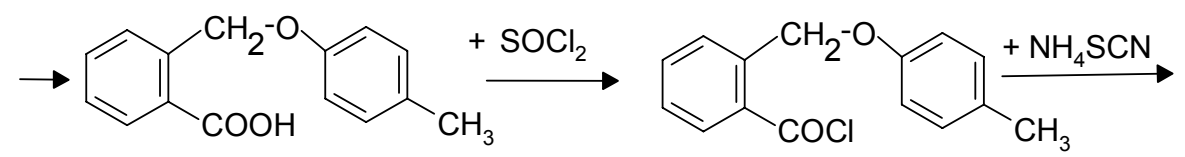

2

3

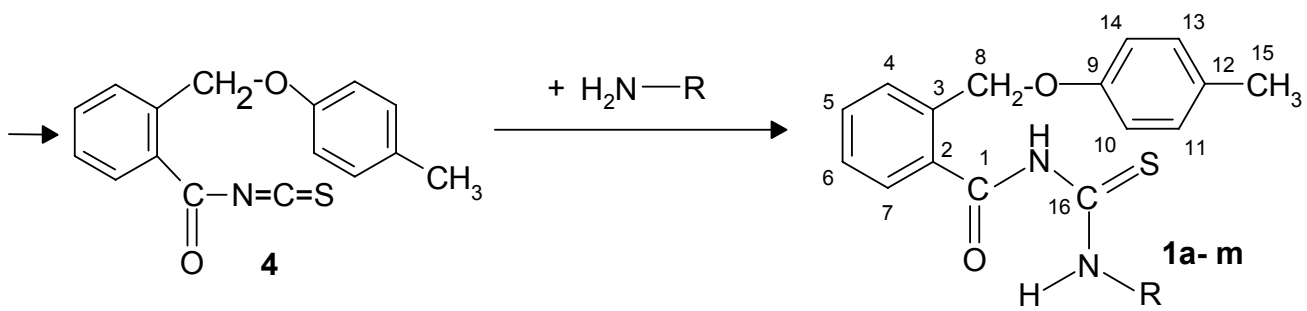<smiles></smiles><smiles>Cc1cccc(Cl)c1Cl</smiles>

$1 b$<smiles>Cc1ccc(Cl)c(Cl)c1</smiles>

1c<smiles>Cc1cc(Cl)c(Cl)cc1Cl</smiles>

$1 d$<smiles>Clc1cc(I)cc(Cl)c1Cl</smiles>

$1 e$<smiles>Cc1ccccc1Br</smiles><smiles>Cc1cc(Br)ccc1Br</smiles>

$1 \mathrm{~h}$

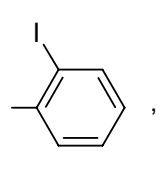

$1 \mathrm{i}$

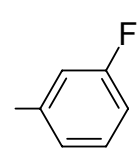

$1 \mathrm{j}$

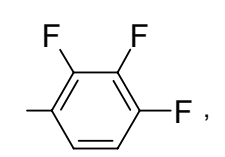

$1 \mathrm{k}$<smiles>Fc1cc(F)c(F)c(F)c1F</smiles> 
The new derivatives 1a-m were synthesized in good yields following the method described by us (Scheme 1). 2-(4-Methylphenoxymethyl)benzoic acid (2) was converted into the corresponding acid chloride 3 using thionyl chloride and anhydrous 1,2-dichloroethane as reaction medium, then treated with a solution of ammonium thiocyanate in acetone to afford arylisothiocyanate $4 \mathrm{in} \mathrm{situ}$, followed by refluxing with amines to provide acylthioureas 1a-m in good yields. The compounds were purified by recrystallization from isopropanol. The acid $\mathbf{2}$ was synthesized with the best yield by using phtalide $\mathbf{5}$, which was treated with potassium para-cresolate in xylene under reflux. The obtained potassium salt 6 of 2-(4-methylphenoxymethyl)benzoic acid, due to its good solubility in 10\% aqueous potassium hydroxide solution allowed its facile separation from xylene. The acid $\mathbf{2}$ was then precipitated using a mineral acid solution. The necessary potassium para-cresolate was obtained from the corresponding phenol and potassium hydroxide in xylene. The resulting water was removed by azeotropic distillation.

The new compounds have all been characterized by their melting point, elemental analysis, infrared and NMR spectral studies. All spectroscopic and elemental analyses data confirm the proposed structures of the new compounds.

\subsection{Biological Activity}

\subsubsection{Antimicrobial Activity}

The emergence of bacterial resistance and multiresistance to antibiotics has been declared by the European Center for Disease Control (ECDC) as one of the major public health problems, besides HIV infection, tuberculosis and influenza. The increasing occurrence of multiresistant pathogenic bacterial strains has gradually rendered traditional antimicrobial treatment ineffective. Consequently, there is a pressing need to develop new antibiotics in order to overcome the bacterial resistance [29].

The qualitative screening of the susceptibility spectra of various microbial strains to the newly synthesized compounds showed that only five of the tested compounds (1c, $\mathbf{1 d}, \mathbf{1 f}, \mathbf{1 i}$ and $\mathbf{1 j}$ ) exhibited an antimicrobial effect quantified by the occurrence of a growth inhibition zone (Table 1). The compounds 1c (substituted with two chloride atoms in positions 3 and 4) and $\mathbf{1 j}$ (containing one fluorine atom in position 3) exhibited activity against S. aureus ATCC 25923 strain, while 1i (containing one iodine atom in position 2) exhibited activity against $S$. aureus 1694 clinical strain. The compound 1d (substituted with three chloride atoms in positions 2, 4 and 5) exhibited antiPseudomonas activity, and $\mathbf{1 f}$ (containing one bromide atom in position 2) was active on $P$. aeruginosa and $K$. pneumoniae strains. The compound $\mathbf{1} \mathbf{j}$ was the only one active both on Gram negative $P$. aeruginosa and the Gram positive $S$. aureus.

The results of the quantitative assay revealed that the serial dilutions of the compounds that proved to be active on different microbial strains in the qualitative screening assay, exhibited a low inhibitory activity on the bacterial growth, with high MIC values of $1,000-500 \mu \mathrm{g} / \mathrm{mL}$ (Table 2). Despite the high MIC values obtained for the tested compounds, we further tested them for their anti-pathogenic features, taking into account that, in many cases, the sub-inhibitory concentrations of the antimicrobial substances interfere with the expression of different virulence features, such are adhesins or toxins [30]. 
Table 1. Results of the qualitative screening of the susceptibility spectra of various microbial strains to the newly synthesized compounds (diameter of the growth inhibition zone expressed in $\mathrm{mm}$ ).

\begin{tabular}{|c|c|c|c|c|c|c|c|c|c|}
\hline \multirow[b]{2}{*}{ Compound } & \multicolumn{9}{|c|}{ Microbial strain } \\
\hline & 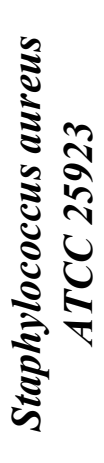 & 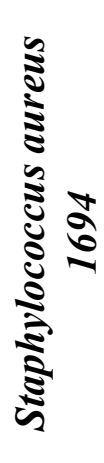 & 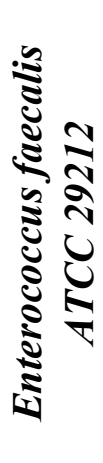 & 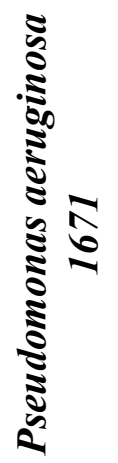 & 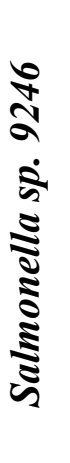 & 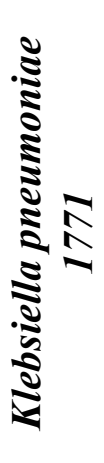 & 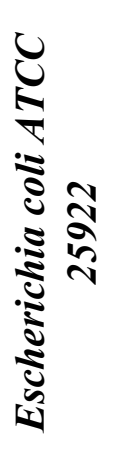 & 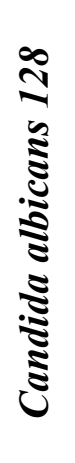 & 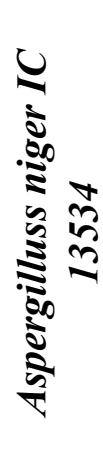 \\
\hline $1 \mathbf{a}$ & 0 & 0 & 0 & 0 & 0 & 0 & 0 & 0 & 0 \\
\hline $1 \mathrm{~b}$ & 0 & 0 & 0 & 0 & 0 & 0 & 0 & 0 & 0 \\
\hline $1 \mathrm{c}$ & 10 & 0 & 0 & 0 & 0 & 0 & 0 & 0 & 0 \\
\hline $1 d$ & 0 & 0 & 0 & 6 & 0 & 0 & 0 & 0 & 0 \\
\hline $1 \mathrm{e}$ & 0 & 0 & 0 & 0 & 0 & 0 & 0 & 0 & 0 \\
\hline 1f & 0 & 0 & 0 & 12 & 0 & 10 & 0 & 0 & 0 \\
\hline $1 g$ & 0 & 0 & 0 & 0 & 0 & 0 & 0 & 0 & 0 \\
\hline $1 \mathrm{~h}$ & 0 & 0 & 0 & 0 & 0 & 0 & 0 & 0 & 0 \\
\hline $1 \mathbf{i}$ & 0 & 11 & 0 & 0 & 0 & 0 & 0 & 0 & 0 \\
\hline $\mathbf{1 j}$ & 10 & 0 & 0 & 6 & 0 & 0 & 0 & 0 & 0 \\
\hline $1 \mathrm{k}$ & 0 & 0 & 0 & 0 & 0 & 0 & 0 & 0 & 0 \\
\hline 11 & 0 & 0 & 0 & 0 & 0 & 0 & 0 & 0 & 0 \\
\hline $1 \mathrm{~m}$ & 0 & 0 & 0 & 0 & 0 & 0 & 0 & 0 & 0 \\
\hline DMSO & 0 & 0 & 0 & 0 & 0 & 0 & 0 & 0 & 0 \\
\hline
\end{tabular}

Table 2. Results of the quantitative assay of MIC for the compounds proving to be active in the qualitative screening on the respective bacterial strains (MIC values expressed in $\mu \mathrm{g} / \mathrm{mL})$.

\begin{tabular}{|l|c|c|c|c|c|}
\cline { 2 - 6 } \multicolumn{1}{c|}{} & \multicolumn{5}{c|}{ Compound } \\
\hline Strain & 1c & 1d & 1f & $\mathbf{1 i}$ & $\mathbf{1 j}$ \\
\hline S. aureus ATCC 25923 & 500 & & & & 500 \\
\hline S. aureus 1694 & & & & 500 & \\
\hline K. pneumoniae 1771 & & & 500 & & \\
\hline P. aeruginosa 1671 & & 1000 & 500 & & 1000 \\
\hline
\end{tabular}

\subsubsection{Antipathogenic Activity}

The genetic resistance of different microbial strains to numerous antimicrobial agents is amplified when one organism is found growing in a biofilm. Antimicrobial resistance is a trait typical of most biofilm organisms and it has been speculated that biofilms are the causative agent of up to $65 \%$ of bacterial infections [31]. Biofilms are thought to become recalcitrant to antimicrobial assault through a number of different mechanisms. 
Giving the increasing risk of antimicrobial resistance, research is focusing on the discovery of anti-pathogenic drugs that block the coordinated expression of virulence factors, such as adherence capacity or production of toxins, thus rendering the bacteria harmless. Contrary to antibiotics, these new anti-pathogenic drugs do not kill the bacteria, and since the survival of the bacteria is not threatened by this approach, the development of resistance, like that to antibiotics, is not anticipated to be a serious problem.

The inert substrata including the prosthetic medical devices represent risk factors for the occurrence of biofilm associated infections. Taking into account the differences in physiology and susceptibility to antibiotics of biofilm-embedded bacteria [32], the compounds active against different bacterial strains in free state were further chosen and investigated concerning their efficiency against the adherent cells grown in biofilms developed in plastic wells. The experimental model uses mini volumes and multiple well plastic plates, allowing the simultaneous testing of a large spectrum of antibiotic concentrations.

Our results showed that the five compounds selected for the quantitative MIC assay proved to be extremely active, inhibiting the ability of the $S$. aureus, Ps. aeruginosa and $K$. pneumoniae strains to adhere and colonize the inert substratum at very low concentrations (with one exception, ranging between $13 \mu \mathrm{g} / \mathrm{mL}$ and $27 \mu \mathrm{g} / \mathrm{mL}$ ), probably due to their interference with adhesins expression (Table 3). Thus, despite their high MICs, the tested substances seem to be promising as antipathogenic compounds, which may be used in low concentrations for prophylaxis or therapy by themselves or in combination with an antibiotic.

Table 3. Results of the quantitative assay of the influence of the tested compounds on the adherence ability and biofilm development on the inert substratum (values of inhibitory concentrations of biofilm development are expressed in $\mu \mathrm{g} / \mathrm{mL}$ ).

\begin{tabular}{|l|c|c|c|c|c|}
\cline { 2 - 6 } \multicolumn{1}{c|}{} & \multicolumn{5}{c|}{ Compound } \\
\hline Strain & 1c & 1d & 1f & $\mathbf{1 i}$ & $\mathbf{1 j}$ \\
\hline S. aureus ATCC 25923 & 13 & & & & 437 \\
\hline S. aureus 1694 & & & & 13 & \\
\hline K. pneumoniae 1771 & & & 27 & & \\
\hline P. aeruginosa 1671 & & 13 & 13 & & 13 \\
\hline
\end{tabular}

\section{Experimental}

\subsection{General}

All chemicals used for the preparation of the compounds were of reagent grade quality and were obtained from Merck, Fluka or Sigma- Aldrich. $p$-Methylphenol was used freshly distilled. Acetone was dried over $\mathrm{K}_{2} \mathrm{CO}_{3}$ and then distilled and ammonium thiocyanate was treated by heating at $100{ }^{\circ} \mathrm{C}$ before use. The necessary liquid amines were dried with potassium hydroxide and afterwards distilled.

Melting points were determined in open capillary tubes on an Electrothermal 9100 apparatus and uncorrected. C, H, N and S analysis were carried out on a Perkin Elmer CHNS/O Analyzer Series II 2400 elemental analyzer. The room temperature attenuated total reflection Fourier transform infrared (FT-IR ATR) spectra of the all synthesized compounds were registered using a Bruker Vertex 70 spectrophotometer. The IR bands are given as $\mathrm{w}$ - weak, $\mathrm{m}$ - medium, s - intense, vs - very intense. 
${ }^{1} \mathrm{H}-\mathrm{NMR}$ and ${ }^{13} \mathrm{C}-\mathrm{NMR}$ spectra were recorded in DMSO- $\mathrm{d}_{6}$ on a Gemini 300BB instrument, at room temperature, operating at $300 \mathrm{MHz}$ for ${ }^{1} \mathrm{H}$ and $75 \mathrm{MHz}$ for ${ }^{13} \mathrm{C}$ and a Unity Inova 400 instrument, operating at $400 \mathrm{MHz}$ for ${ }^{1} \mathrm{H}$ and $100 \mathrm{MHz}$ for ${ }^{13} \mathrm{C}$. Chemical shifts were given as $\delta$ values in parts per million (ppm) relative to tetramethylsilane as internal standard. Coupling constants J were given in $\mathrm{Hz}$. Spin multiplets are given as s (singlet), d (doublet), $\mathrm{t}$ (triplet), q (quartet), m (multiplet), dd (double doublet), td (triple doublet) and br (broad). The chemical shifts for hydrogen and carbon atoms were established also by G-COSY, G-HSQC, G-HMBC experiments. The 2-(4-methylphenoxymethyl)benzoic acid and 2-(4-methyl-phenoxymethyl)benzoyl chloride derivatives were obtained in good yields similar to those reported in the previous article [33].

\subsubsection{General Synthesis Procedure of the New Thioureides}

A solution of 2-(4-methylphenoxymethyl)benzoyl chloride $(0.01 \mathrm{~mol})$ in acetone $(15 \mathrm{~mL})$ was added to a solution of ammonium thiocyanate $(0.01 \mathrm{~mol})$ in acetone $(5 \mathrm{~mL})$. The reaction mixture was heated under reflux for $1 \mathrm{~h}$, and then cooled at the room temperature. A solution of primary amine $(0.01 \mathrm{~mol})$ in acetone $(2 \mathrm{~mL})$ was added to the mixture and heated under reflux for $1 \mathrm{~h}$. The thioureide was precipitated after the cooled reaction mixture was poured into $500 \mathrm{~mL}$ water. The solid product was purified by recrystallization from isopropanol with active carbon.

\subsubsection{Spectral Data}

2-((4-Methylphenoxy)methyl)-N-(3,5-dichlorophenylcarbamothioyl)benzamide (1a); yield 70\%, mp 197.1-198.9 ${ }^{\circ} \mathrm{C}$. ${ }^{1} \mathrm{H}-\mathrm{NMR}: 12.31$ (s, 1H, NH, D $\mathrm{O}$ exchangeable); 11.98 (br s, $1 \mathrm{H}, \mathrm{NH}, \mathrm{D}_{2} \mathrm{O}$ exchangeable); 7.67 (d, $J=1.7 \mathrm{~Hz}, 2 \mathrm{H}, \mathrm{H}-18, \mathrm{H}-22) ; 7.61$ (bd, $J=7.4 \mathrm{~Hz}, 1 \mathrm{H}, \mathrm{H}-7) ; 7.58$ (dd, $J=1.6 \mathrm{~Hz}$, $J=7.4 \mathrm{~Hz}, 1 \mathrm{H}, \mathrm{H}-4) ; 7.55$ (td, $J=1.4 \mathrm{~Hz}, J=7.4 \mathrm{~Hz}, 1 \mathrm{H}, \mathrm{H}-5) ; 7.50$ (t, $J=1.7 \mathrm{~Hz}, 1 \mathrm{H}, \mathrm{H}-20) ; 7.46$ $(\mathrm{td}, J=1.4 \mathrm{~Hz}, J=7.8 \mathrm{~Hz}, 1 \mathrm{H}, \mathrm{H}-6) ; 7.05$ (d, $J=8.6 \mathrm{~Hz}, 2 \mathrm{H}, \mathrm{H}-11, \mathrm{H}-13) ; 6.87$ (d, $J=8.6 \mathrm{~Hz}, 2 \mathrm{H}$, H-10, H-14); 5.26 (s, 2H, H-8); 2.22 (s, 3H, H-15); ${ }^{13} \mathrm{C}-\mathrm{NMR}: 179.34$ (C-16); 169.92 (C-1); 156.05 (C-9); 140.19 (C-3); 135.80 (C-19, C-21); 133.52 (C-2); 133.18 (C-12); 130.98 (C-5); 129.69 (C-11, C-13); 129.58 (C-17); 128.35 (C-4); 128.23 (C-7); 127.68 (C-6); 125.51 (C-20); 123.07 (C-18, C-22); 114.42 (C-10, C-14); 67.41 (C-8); 19.99 (C-15); FT-IR $\left(v \mathrm{~cm}^{-1}\right)$ : 3278m; 3075w; 3018w; 2914w; $2857 \mathrm{w} ; 1675 \mathrm{~m} ; 1621 \mathrm{w} ; 1575 \mathrm{~m} ; 1543 \mathrm{~s} ; 1513 \mathrm{vs} ; 1440 \mathrm{~m} ; 1386 \mathrm{~m} ; 1315 \mathrm{~m} ; 1292 \mathrm{~m} ; 1243 \mathrm{~s} ; 1160 \mathrm{~s} ;$ $1107 \mathrm{w} ; 1042 \mathrm{~m} ; 988 \mathrm{w} ; 885 \mathrm{w} ; 854 \mathrm{w} ; 815 \mathrm{w} ; 798 \mathrm{w} ; 752 \mathrm{~m} ; 689 \mathrm{~m} ; 651 \mathrm{w} ; 607 \mathrm{w}$; Anal. Calcd for $\mathrm{C}_{22} \mathrm{H}_{18} \mathrm{Cl}_{2} \mathrm{~N}_{2} \mathrm{O}_{2} \mathrm{~S}$ (445.36): C, 59.33; H, 4.07; N, 6.29; S, 7.20\%; Found: C, 59.65; H, 4.23; N, 6.34; $\mathrm{S} 7.25 \%$.

2-((4-Methylphenoxy)methyl)-N-(2,3-dichlorophenylcarbamothioyl)benzamide (1b); yield 65\%, mp 152.4-153.2 ${ }^{\circ} \mathrm{C}$; ${ }^{1} \mathrm{H}-\mathrm{NMR}: 12.43$ (s, $1 \mathrm{H}, \mathrm{NH}, \mathrm{D}_{2} \mathrm{O}$ exchangeable); 12.12 (br s, $1 \mathrm{H}, \mathrm{NH}, \mathrm{D}_{2} \mathrm{O}$ exchangeable); 7.87 (dd, $J=1.2 \mathrm{~Hz}, J=8.2 \mathrm{~Hz}, 1 \mathrm{H}, \mathrm{H}-22) ; 7.64$ (dd, $J=1.2 \mathrm{~Hz}, J=8.2 \mathrm{~Hz}, 1 \mathrm{H}, \mathrm{H}-20$ ); 7.61 (bd, $J=7.4 \mathrm{~Hz}, 1 \mathrm{H}, \mathrm{H}-7) ; 7.58$ (dd, $J=1.6 \mathrm{~Hz}, J=7.4 \mathrm{~Hz}, 1 \mathrm{H}, \mathrm{H}-4) ; 7.55$ (td, $J=1.4 \mathrm{~Hz}$, $J=7.4 \mathrm{~Hz}, 1 \mathrm{H}, \mathrm{H}-5) ; 7.46$ (td, $J=1.4 \mathrm{~Hz}, J=7.8 \mathrm{~Hz}, 1 \mathrm{H}, \mathrm{H}-6) ; 7.41$ (t, $J=8.2 \mathrm{~Hz}, 1 \mathrm{H}, \mathrm{H}-21) ; 7.05$ (d, $J=8.6 \mathrm{~Hz}, 2 \mathrm{H}, \mathrm{H}-11, \mathrm{H}-13) ; 6.88$ (d, $J=8.6 \mathrm{~Hz}, 2 \mathrm{H}, \mathrm{H}-10, \mathrm{H}-14) ; 5.27$ (s, 2H, H-8); 2.21 (s, 3H, H-15); ${ }^{13}$ C-NMR: 180.15 (C-16); 170.17 (C-1); 156.02 (C-9); 137.35 (C-3); 135.77 (C-2); 133.13 (C-12); 131.77 (C-19); 129.61 (C-17); 127.33 (C-18); 131.02 (C-5); 129.69 (C-11, C-13); 128.51 
(C-20); 128.48 (C-4); 128.40 (C-7); 127.73 (C-21); 127.64 (C-6); 126.80 (C-22); 114.51 (C-10, C-14); $67.51(\mathrm{C}-8) ; 19.99(\mathrm{C}-15)$; FT-IR $\left(\mathrm{v} \mathrm{cm}^{-1}\right): 3252 \mathrm{w} ; 3120 \mathrm{w} ; 3026 \mathrm{w} ; 2912 \mathrm{w} ; 2855 \mathrm{w} ; 1680 \mathrm{~m} ; 1573 \mathrm{~m}$; $1510 \mathrm{vs} ; 1444 \mathrm{~m} ; 1418 \mathrm{~m} ; 1381 \mathrm{~m} ; 1318 \mathrm{~m} ; 1294 \mathrm{~m} ; 1240 \mathrm{~s} ; 1197 \mathrm{~m} ; 1163 \mathrm{~s} ; 1124 \mathrm{~m} ; 1108 \mathrm{~m} ; 1038 \mathrm{~m}$; 968w; 873w; 856w; 818w; 804w; 777w; 747m; 727m; 696m; 658m; 607w; 571w; Anal. Calcd for $\mathrm{C}_{22} \mathrm{H}_{18} \mathrm{Cl}_{2} \mathrm{~N}_{2} \mathrm{O}_{2} \mathrm{~S}$ (445.36): C, 59.33; H, 4.07; N, 6.29; S, 7.20\%; Found: C, 59.68; H, 4.15; N, 6.24; $\mathrm{S} 7.37 \%$.

2-((4-Methylphenoxy)methyl)-N-(3,4-dichlorophenylcarbamothioyl)benzamide (1c); yield 55\%, mp 172.1-174.3 ${ }^{\circ} \mathrm{C}$; ${ }^{1} \mathrm{H}-\mathrm{NMR}: 12.33$ (s, 1H, NH, $\mathrm{D}_{2} \mathrm{O}$ exchangeable); 11.98 (br s, $1 \mathrm{H}, \mathrm{NH}, \mathrm{D}_{2} \mathrm{O}$ exchangeable); 7.97 (d, $J=2.3 \mathrm{~Hz}, 1 \mathrm{H}, \mathrm{H}-18) ; 7.65$ (d, $J=8.8 \mathrm{~Hz}, 1 \mathrm{H}, \mathrm{H}-21) ; 7.54$ (dd, $J=2.3 \mathrm{~Hz}$, $J=8.8 \mathrm{~Hz}, 1 \mathrm{H}, \mathrm{H}-22) ; 7.61$ (bd, $J=7.4 \mathrm{~Hz}, 1 \mathrm{H}, \mathrm{H}-7) ; 7.58(\mathrm{dd}, J=1.6 \mathrm{~Hz}, J=7.4 \mathrm{~Hz}, 1 \mathrm{H}, \mathrm{H}-4)$; 7.57 (dd, $J=1.6 \mathrm{~Hz}, J=8.2 \mathrm{~Hz}, 1 \mathrm{H}, \mathrm{H}-22) ; 7.55$ (td, $J=1.4 \mathrm{~Hz}, J=7.4 \mathrm{~Hz}, 1 \mathrm{H}, \mathrm{H}-5) ; 7.46$ (td, $J=1.4 \mathrm{~Hz}, J=7.8 \mathrm{~Hz}, 1 \mathrm{H}, \mathrm{H}-6) ; 7.05$ (d, $J=8.6 \mathrm{~Hz}, 2 \mathrm{H}, \mathrm{H}-11, \mathrm{H}-13) ; 6.87$ (d, $J=8.6 \mathrm{~Hz}, 2 \mathrm{H}$, $\mathrm{H}-10, \mathrm{H}-14) ; 5.26$ (s, 2H, H-8); 2.21 (s, 3H, H-15); ${ }^{13} \mathrm{C}-\mathrm{NMR}: 179.18$ (C-16); 169.90 (C-1); 156.04 (C-9); 137.88 (C-18); 135.80 (C-2); 133.16 (C-12); 130.58 (C-19); 130.98 (C-5); 130.29 (C-22); 129.70 (C-11, C-13); 129.59 (C-17); 128.39 (C-4); 128.26 (C-7); 128.07 (C-20); 127.65 (C-6); 125.92 (C-18); 124.73 (C-21); 114.46 (C-10, C-14); 67.40 (C-8); 19.98 (C-15); FT-IR (v cm $\left.{ }^{-1}\right)$ : 3330m; 2969m; 1679m; 1601m; 1584m; 1505vs; 1469s; 1443s; 1384m; 1332m; 1293m; 1227s; 1173s; 1144s; 1050w; 1026s; 971w; 873w; 853w;821m; 787w; 749m; 709m; 664m; 608w; 567w; Anal. Calcd for $\mathrm{C}_{22} \mathrm{H}_{18} \mathrm{Cl}_{2} \mathrm{~N}_{2} \mathrm{O}_{2} \mathrm{~S}$ (445.36): C, 59.33; H, 4.07; N, 6.29; S, 7.20\%; Found: C, 59.76; H, 3.96; N, 6.21; $\mathrm{S} 7.23 \%$.

2-((4-Methylphenoxy)methyl)-N-(2,4,5-trichlorophenylcarbamothioyl)benzamide (1d); yield 58\%, mp 171.8-173.4 ${ }^{\circ} \mathrm{C}$; ${ }^{1} \mathrm{H}-\mathrm{NMR}: 12.47$ (br s, $1 \mathrm{H}, \mathrm{NH}$ ); 12.20 (br s, $1 \mathrm{H}, \mathrm{NH}$ ); 8.28 (s, 1H, H-22); 7.97 (s, 1H, H-19); 7.62 (bd, $J=7.4 \mathrm{~Hz}, 1 \mathrm{H}, \mathrm{H}-7) ; 7.58$ (dd, $J=1.6 \mathrm{~Hz}, J=7.4 \mathrm{~Hz}, 1 \mathrm{H}, \mathrm{H}-4) ; 7.55$ (td, $J=1.4 \mathrm{~Hz}, J=7.4 \mathrm{~Hz}, 1 \mathrm{H}, \mathrm{H}-5) ; 7.46(\mathrm{td}, J=1.4 \mathrm{~Hz}, J=7.5 \mathrm{~Hz}, 1 \mathrm{H}, \mathrm{H}-6) ; 7.04$ (d, $J=8.6 \mathrm{~Hz}, 2 \mathrm{H}$, H-11, H-13); 6.86 (d, $J=8.62$ Hz, H, H-10, H-14); 5.26 (s, 2H, H-8); 2.21 (s, 3H, H-15); ${ }^{13} \mathrm{C}-\mathrm{NMR}$ : 179.89 (C-16); 170.23 (C-1); 156.01 (C-9); 135.75 (C-3); 135.49 (C-2); 133.11 (C-12); 131.05 (C-5); 130.40 (C-19); 129.66 (C-11, C-13); 129.58 (C-20); 129.32 (C-17); 129.31 (C-7); 128.71 (C-21); 128.48 (C-4); 128.27 (C-22); 127.87 (C-18); 127.77 (C-6); 114.44 (C-10, C-14); 67.51 (C-8); 19.99 $(\mathrm{C}-15)$; FT-IR $\left(\mathrm{v} \mathrm{cm}^{-1}\right)$ : 3553w; 3094w; 2989w; 2917w; 1678m;1603w;1566s; 1511vs; 1462m; $1446 \mathrm{~m} ; 1391 \mathrm{w} ; 1364 \mathrm{w} ; 1311 \mathrm{~m} ; 1260 \mathrm{~m} ; 1242 \mathrm{~s} ; 1165 \mathrm{~s} ; 1127 \mathrm{w} ; 1078 \mathrm{w} ; 1070 \mathrm{w} ; 1052 \mathrm{~m} ; 1040 \mathrm{~m} ; 895 \mathrm{w} ;$ $878 \mathrm{w} ; 857 \mathrm{w} ; 835 \mathrm{w} ; 814 \mathrm{w} ; 799 \mathrm{~m} ; 753 \mathrm{~m} ; 699 \mathrm{~m} ; 668 \mathrm{w} ; 613 \mathrm{w} ; 564 \mathrm{w}$. Anal. Calcd for $\mathrm{C}_{22} \mathrm{H}_{17} \mathrm{Cl}_{3} \mathrm{~N}_{2} \mathrm{O}_{2} \mathrm{~S}$ (479.80): C, 55.04; H, 3.57; N, 5.84; S, 6.68\%; Found: C, 55.31; H, 3.59; N, 5.71; S 6.60\%.

2-((4-Methylphenoxy)methyl)-N-(3,4,5-trichlorophenylcarbamothioyl)benzamide (1e); yield 67\%, mp 158.7-160.8 ${ }^{\circ} \mathrm{C} .{ }^{1} \mathrm{H}-\mathrm{NMR}: 12.16$ (br s, 2H, NH); 7.90 (s, 2H, H-18, H-22); 7.62 (bd, J = $7.4 \mathrm{~Hz}, 1 \mathrm{H}$, H-7); 7.58 (dd, $J=1.6 \mathrm{~Hz}, J=7.4 \mathrm{~Hz}, 1 \mathrm{H}, \mathrm{H}-4) ; 7.55$ (td, $J=1.4 \mathrm{~Hz}, J=7.4 \mathrm{~Hz}, 1 \mathrm{H}, \mathrm{H}-5) ; 7.46$ (td, $J=1.4 \mathrm{~Hz}, J=7.5 \mathrm{~Hz}, 1 \mathrm{H}, \mathrm{H}-6) ; 7.05$ (d, $J=8.6 \mathrm{~Hz}, 2 \mathrm{H}, \mathrm{H}-11, \mathrm{H}-13) ; 6.87$ (d, $J=8.6 \mathrm{~Hz}, 2 \mathrm{H}, \mathrm{H}-10$, $\mathrm{H}-14$ ); 5.26 (s, 2H, H-8); 2.21 (s, 3H, H-15). ${ }^{13} \mathrm{C}-\mathrm{NMR}: 179.51$ (C-16); 169.87 (C-1); 156.04 (C-9); 137.90 (C-3); 135.82 (C-2); 133.10 (C-12); 132.32 (C-19, C-21); 129.59 (C-17); 126.79 (C-20); 131.03 (C-5); 129.69 (C-11, C-13); 128.36 (C-7); 128.29 (C-4); 127.69 (C-6); 125.06 (C-18, C-22); 114.42 (C-10, C-14); 67.40 (C-8); $20.00(\mathrm{C}-15)$. FT-IR $\left(v \mathrm{~cm}^{-1}\right): 3290 \mathrm{w} ; 3079 \mathrm{w} ; 2912 \mathrm{w} ; 1682 \mathrm{~m}$; 
$1588 \mathrm{w} ; 1561 \mathrm{~m} ; 1536 \mathrm{~m} ; 1509 \mathrm{vs} ; 1431 \mathrm{~m} ; 1381 \mathrm{~m} ; 1309 \mathrm{~m} ; 1248 \mathrm{~s} ; 1238 \mathrm{~s} ; 1992 \mathrm{w} ; 1169 \mathrm{~s} ; 1150 \mathrm{~m} ;$ 1053w; 1039m; 887w; 860w; 813w; 804w; 782w; 752m; 718w; 688w; 666m; 611w. Anal. Calcd for $\mathrm{C}_{22} \mathrm{H}_{17} \mathrm{Cl}_{3} \mathrm{~N}_{2} \mathrm{O}_{2} \mathrm{~S}$ (479.80): C, 55.04; H, 3.57; N, 5.84; S, 6.68\%; Found: C, 55.29; H, 3.52; N, 5.91; S $6.76 \%$.

2-((4-Methylphenoxy)methyl)-N-(2-bromophenylcarbamothioyl)benzamide (1f); yield $62 \%, \quad \mathrm{mp}$ 144.5-145.7 ${ }^{\circ} \mathrm{C} .{ }^{1} \mathrm{H}-\mathrm{NMR}: 12.38$ (br s, $1 \mathrm{H}, \mathrm{NH}$ ); 12.02 (br s, $\left.1 \mathrm{H}, \mathrm{NH}\right) ; 7.85$ (dd, $J=1.5 \mathrm{~Hz}, J=8.1 \mathrm{~Hz}$, $1 \mathrm{H}, \mathrm{H}-22) ; 7.71$ (dd, $J=1.5 \mathrm{~Hz}, J=8.1 \mathrm{~Hz}, 1 \mathrm{H}, \mathrm{H}-19) ; 7.62(\mathrm{dd}, J=1.7 \mathrm{~Hz}, J=6.6 \mathrm{~Hz}, 1 \mathrm{H}$, H-7); 7.58 (dd, $J=2.4 \mathrm{~Hz}, J=7.4 \mathrm{~Hz}, 1 \mathrm{H}, \mathrm{H}-4) ; 7.55$ (td, $J=1.7 \mathrm{~Hz}, J=8.9 \mathrm{~Hz}, 1 \mathrm{H}, \mathrm{H}-5) ; 7.47$ $(\mathrm{ddd}, J=2.4 \mathrm{~Hz}, J=6.6 \mathrm{~Hz}, J=8.9 \mathrm{~Hz}, 1 \mathrm{H}, \mathrm{H}-6) ; 7.43(\mathrm{ddd}, J=1.5 \mathrm{~Hz}, J=7.3 \mathrm{~Hz}, J=8.1 \mathrm{~Hz}, 1 \mathrm{H}$, $\mathrm{H}-21) ; 7.24$ (ddd, $J=1.5 \mathrm{~Hz}, J=7.3 \mathrm{~Hz}, J=8.1 \mathrm{~Hz}, 1 \mathrm{H}, \mathrm{H}-20) ; 7.06$ (d, $J=8.6 \mathrm{~Hz}, 2 \mathrm{H}, \mathrm{H}-11, \mathrm{H}-13$ ); 6.88 (d, $J=8.6 \mathrm{~Hz}, 2 \mathrm{H}, \mathrm{H}-10, \mathrm{H}-14) ; 5.27$ (s, 2H, H-8); 2.21 (br s, 3H, H-15). The doublet signal of the protons $\mathrm{H}-11$ and $\mathrm{H}-13$ in the ${ }^{1} \mathrm{H}-\mathrm{NMR}$ spectrum is further split by the methyl group. Scalar coupling is experimentally measured and the value has ${ }^{4} J(\mathrm{H} 11, \mathrm{H} 13-\mathrm{CH} 3)=0.6 \mathrm{~Hz} .{ }^{13} \mathrm{C}-\mathrm{NMR}: 179.99$ (C-16); 170.17 (C-1); 156.01 (C-9); 136.60 (C-3); 135.70 (C-2); 133.19 (C-12); 129.63 (C-17); 118.96 (C-18); 135.70 (C-19); 132.53 (C-20); 130.99 (C-5); 129.69 (C-11, C-13); 128.51 (C-7); 128.49 (C22); 128.42 (C-21); 127.73 (C-6); 127.64 (C-20); 114.52 (C-10, C-14); 67.45 (C-8); 19.99 $(\mathrm{C}-15)$. FT-IR $\left(\mathrm{v} \mathrm{cm}^{-1}\right): 3232 \mathrm{w} ; 3027 \mathrm{w} ; 2918 \mathrm{w} ; 2857 \mathrm{w} ; 1675 \mathrm{~m} ; 1578 \mathrm{w} ; 1513 \mathrm{vs} ; 1441 \mathrm{~m} ; 1387 \mathrm{w} ; 1317 \mathrm{w}$; $1287 \mathrm{w} ; 1242 \mathrm{~s} ; 1161 \mathrm{~s} ; 1042 \mathrm{~m} ; 853 \mathrm{w} ; 801 \mathrm{w} ; 742 \mathrm{~m} ; 707 \mathrm{~m} ; 672 \mathrm{w} ; 608 \mathrm{w}$. Anal. Calcd for $\mathrm{C}_{22} \mathrm{H}_{19} \mathrm{BrN}_{2} \mathrm{O}_{2} \mathrm{~S}$ (455.36): C, 58.02; H, 4.21; N, 6.15; S, 7.04\%; Found: C, 57.89; H, 4.28; N, 6.11; S 7.16\%.

2-((4-Methylphenoxy)methyl)-N-(2,4-dibromophenylcarbamothioyl)benzamide (1g); yield 67\%, mp 169.3-170.6 ${ }^{\circ} \mathrm{C} .{ }^{1} \mathrm{H}-\mathrm{NMR}: 12.33$ (br s, $\left.1 \mathrm{H}, \mathrm{NH}\right) ; 12.10$ (br s, $\left.1 \mathrm{H}, \mathrm{NH}\right) ; 7.95$ (d, $J=1.4 \mathrm{~Hz}, 1 \mathrm{H}$, H-19); 7.80 (d, $J=8.6 \mathrm{~Hz}, 1 \mathrm{H}, \mathrm{H}-22) ; 7.64$ (dd, $J=1.4 \mathrm{~Hz}, J=8.6 \mathrm{~Hz}, 1 \mathrm{H}, \mathrm{H}-21) ; 7.62$ (bd, $J=7.4$ $\mathrm{Hz}, 1 \mathrm{H}, \mathrm{H}-7) ; 7.58$ (dd, $J=1.6 \mathrm{~Hz}, J=7.4 \mathrm{~Hz}, 1 \mathrm{H}, \mathrm{H}-4) ; 7.55$ (td, $J=1.4 \mathrm{~Hz}, J=7.4 \mathrm{~Hz}, 1 \mathrm{H}, \mathrm{H}-5$ ); 7.46 (td, $J=1.4 \mathrm{~Hz}, J=7.5 \mathrm{~Hz}, 1 \mathrm{H}, \mathrm{H}-6) ; 7.05$ (d, $J=8.6 \mathrm{~Hz}, 2 \mathrm{H}, \mathrm{H}-11, \mathrm{H}-13) ; 6.87$ (d, $J=8.6 \mathrm{~Hz}$, 2H, H-10, H-14); 5.26 (s, 2H, H-8); 2.21 (br s, 3H, H-15). ${ }^{13} \mathrm{C}-\mathrm{NMR}: 180.00$ (C-16); 170.12 (C-1); 155.99 (C-9); 136.36 (C-3); 135.74 (C-2); 133.11 (C-12); 129.58 (C-17); 120.22 (C-20); 119.64 (C-18); 134.41 (C-19); 131.03 (C-5); 130.64 (C-21); 129.82 (C-22); 129.69 (C-4); 129.69 (C-11, C-13); 128.49 (C-7); 127.72 (C-6); 114.51 (C-10, C-14); 67.43 (C-8); 19.99 (C-15). FT-IR ( $\left.v_{\text {cm}}{ }^{-1}\right)$ : 3261w; 3130w; $3032 \mathrm{w} ; 2913 \mathrm{w} ; 2855 \mathrm{w} ; 1679 \mathrm{~m} ; 1615 \mathrm{w} ; 1560 \mathrm{~m} ; 1512 \mathrm{vs} ; 1443 \mathrm{w} ; 1376 \mathrm{w} ; 1295 \mathrm{w} ; 1246 \mathrm{~s} ; 1163 \mathrm{~s} ; 1078 \mathrm{w}$; 1038m; 972w; 942w; 860w; 801w; 781w; 755w; 672m; 601w; 541w. Anal. Calcd for $\mathrm{C}_{22} \mathrm{H}_{18} \mathrm{Br}_{2} \mathrm{~N}_{2} \mathrm{O}_{2} \mathrm{~S}$ (534.26): C, 49.46; H, 3.40; N, 5.24; S, 6.00\%; Found: C, 49.79; H, 3.29; N, 5.33; S 5.89\%.

2-((4-Methylphenoxy)methyl)-N-(2,5-dibromophenylcarbamothioyl)benzamide (1h); yield 69\%, mp 160.2-161.5 ${ }^{\circ} \mathrm{C} .{ }^{1} \mathrm{H}-\mathrm{NMR}: 12.39$ (br s, $1 \mathrm{H}, \mathrm{NH}$ ); 12.12 (br s, 1H, NH); 8.04 (d, $J=2.1 \mathrm{~Hz}, 1 \mathrm{H}, \mathrm{H}-22$ ); 7.66 (d, $J=8.5 \mathrm{~Hz}, 1 \mathrm{H}, \mathrm{H}-19) ; 7.62$ (bd, $J=7.4 \mathrm{~Hz}, 1 \mathrm{H}, \mathrm{H}-7) ; 7.58$ (dd, $J=1.6 \mathrm{~Hz}, J=7.4 \mathrm{~Hz}, 1 \mathrm{H}$, $\mathrm{H}-4) ; 7.55$ (td, $J=1.4 \mathrm{~Hz}, J=7.4 \mathrm{~Hz}, 1 \mathrm{H}, \mathrm{H}-5) ; 7.46$ (td, $J=1.4 \mathrm{~Hz}, J=7.5 \mathrm{~Hz}, 1 \mathrm{H}, \mathrm{H}-6$ ); 7.43 (dd, $J=2.1 \mathrm{~Hz}, J=8.5 \mathrm{~Hz}, 1 \mathrm{H}, \mathrm{H}-20) ; 7.05$ (d, $J=8.6 \mathrm{~Hz}, 2 \mathrm{H}, \mathrm{H}-11, \mathrm{H}-13) ; 6.87$ (d, $J=8.6 \mathrm{~Hz}, 2 \mathrm{H}$, H-10, H-14); 5.26 (s, 2H, H-8); 2.20 (br s, 3H, H-15). ${ }^{13} \mathrm{C}-\mathrm{NMR}: 179.93$ (C-16); 170.15 (C-1); 156.00 (C-9); 138.18 (C-3); 135.68 (C-2); 133.21 (C-12); 129.57 (C-17); 119.60 (C-18); 118.25 (C-21); 134.09 (C-19); 131.00 (C-5); 130.95 (C-20); 130.61 (C-22); 129.67 (C-11, C-13); 128.50 (C-4); 128.43 (C-7); 127.77 (C-6); 114.44 (C-10, C-14); 67.50 (C-8); 20.03 (C-15). FT-IR (v cm $\left.{ }^{-1}\right)$ : 3241m; 
2997w; 2916w; 1675m; 1567m; 1513vs; 1395m; 1313m; 1240s; 1160s; 1075w; 1043m; 957w; 874w; 814w; 790m; 754m; 700m; 608w; 562w. Anal. Calcd for $\mathrm{C}_{22} \mathrm{H}_{18} \mathrm{Br}_{2} \mathrm{~N}_{2} \mathrm{O}_{2} \mathrm{~S}$ (534.26): C, 49.46; H, 3.40; N, 5.24; S, 6.00\%; Found: C, 49.21; H, 3.28; N, 5.15; S 6.07\%.

2-((4-Methylphenoxy)methyl)-N-(2-iodophenylcarbamothioyl)benzamide (1i); yield $94 \%, \quad \mathrm{mp}$ 134.4-136.2 ${ }^{\circ} \mathrm{C} .{ }^{1} \mathrm{H}-\mathrm{NMR}: 12.22$ (br s, $1 \mathrm{H}, \mathrm{NH}$ ); 12.00 (br s, $\left.1 \mathrm{H}, \mathrm{NH}\right) ; 7.92$ (dd, $J=1.4 \mathrm{~Hz}, J=7.9$ Hz, 1H, H-19); 7.65-7.55(m, 4H, H-4, H-5, H-7, H-22); 7.46 (td, $J=1.4 \mathrm{~Hz}, J=7.5 \mathrm{~Hz}, 1 \mathrm{H}, \mathrm{H}-6$ ); $7.44(\mathrm{td}, J=7.9 \mathrm{~Hz}, 1 \mathrm{H}, \mathrm{H}-21) ; 7.07$ (dd, $J=1.5 \mathrm{~Hz}, J=7.9 \mathrm{~Hz}, 1 \mathrm{H}, \mathrm{H}-20) ; 7.05$ (d, $J=8.6 \mathrm{~Hz}, 2 \mathrm{H}$, H-11, H-13); 6.87 (d, $J=8.6$ Hz, 2H, H-10, H-14,); 5.27 (s, 2H, H-8); 2.22 (s, 3H, H-15). ${ }^{13} \mathrm{C}-\mathrm{NMR}$ : 180.13 (C-16); 170.07 (C-1); 156.01 (C-9); 140.06 (C-17); 139.77 (C-19); 135.69 (C-3); 133.19 (C-2); 131.02 (C-5); 129.72 (C-11, C-13); 129.56 (C-12); 128.74 (C-22); 128.57 (C-20); 128.52 (C-4); 128.45 (C-7); 128.36 (C-21); 127.72 (C-6); 114.56 (C-10, C-14); 96.89 (C-18); 67.35 (C-8); 19.98 (C-15). FT-IR $\left(\mathrm{v} \mathrm{cm}^{-1}\right): 3389 \mathrm{~s} ; 3153 \mathrm{w} ; 3029 \mathrm{w} ; 2924 \mathrm{w} ; 1684 \mathrm{~m} ; 1608 \mathrm{w} ; 1511 \mathrm{vs} ; 1485 \mathrm{vs} ; 1379 \mathrm{~m} ; 1354 \mathrm{~m} ; 1308 \mathrm{~m} ; 1237 \mathrm{~s}$; $1142 \mathrm{~s} ; 1068 \mathrm{w} ; 1019 \mathrm{~m} ; 877 \mathrm{w} ; 795 \mathrm{w} ; 743 \mathrm{~m} ; 716 \mathrm{w} ; 653 \mathrm{~m} ; 595 \mathrm{w} ; 515 \mathrm{w}$. Anal. Calcd for $\mathrm{C}_{22} \mathrm{H}_{19} \mathrm{IN}_{2} \mathrm{O}_{2} \mathrm{~S}$ (502.36): C, 52.60; H, 3.81; N, 5.58; S, 6.38\%; Found: C, 52.86; H, 3.97; N, 5.43; S 6.34\%.

2-((4-Methylphenoxy)methyl)-N-(3-fluorophenylcarbamothioyl)benzamide (1j); yield $\quad 76 \%, \quad \mathrm{mp}$ 116.9-119 ${ }^{\circ} \mathrm{C} .{ }^{1} \mathrm{H}-\mathrm{NMR}: 12.48$ (br s, $\left.1 \mathrm{H}, \mathrm{NH}\right) ; 11.89$ (br s, $\left.1 \mathrm{H}, \mathrm{NH}\right) ; 7.69$ (bd, ${ }^{3} J_{(\mathrm{F}-\mathrm{H})}=10.9 \mathrm{~Hz}, 1 \mathrm{H}$, H-18); 7.62 (bd, $J=7.4 \mathrm{~Hz}, 1 \mathrm{H}, \mathrm{H}-7) ; 7.58$ (dd, $J=1.6 \mathrm{~Hz}, J=7.4 \mathrm{~Hz}, 1 \mathrm{H}, \mathrm{H}-4) ; 7.55$ (td, $J=1.4$ $\mathrm{Hz}, J=7.4 \mathrm{~Hz}, 1 \mathrm{H}, \mathrm{H}-5) ; 7.46(\mathrm{td}, J=1.4 \mathrm{~Hz}, J=7.5 \mathrm{~Hz}, 1 \mathrm{H}, \mathrm{H}-6) ; 7.43\left(\mathrm{dd},{ }^{3} J_{(\mathrm{H}-22-\mathrm{H}-21)}=8.2 \mathrm{~Hz}\right.$, $\left.{ }^{3} J_{(\mathrm{H}-20-\mathrm{H}-21)}=8.6 \mathrm{~Hz}, 1 \mathrm{H}, \mathrm{H}-21\right) ; 7.34(\mathrm{ddd}, J=1.1 \mathrm{~Hz}, J=1.9 \mathrm{~Hz}, J=8.2 \mathrm{~Hz}, 1 \mathrm{H}, \mathrm{H}-22) ; 7.10$ (tdd, $\left.{ }^{3} J_{(\mathrm{F}-\mathrm{H})}=8.6 \mathrm{~Hz},{ }^{3} J_{(\mathrm{H}-20-\mathrm{H}-21)}=8.6 \mathrm{~Hz},{ }^{3} J_{(\mathrm{H} 20-\mathrm{H} 21)}=1.9 \mathrm{~Hz},{ }^{3} J_{(\mathrm{H}-20-\mathrm{H}-18)}=1.4 \mathrm{~Hz}, 1 \mathrm{H}, \mathrm{H}-20\right) ; 7.05(\mathrm{~d}, J=8.6$ $\mathrm{Hz}, 2 \mathrm{H}, \mathrm{H}-11, \mathrm{H}-13$ ); 6.87 (d, $J=8.6 \mathrm{~Hz}, 2 \mathrm{H}, \mathrm{H}-10, \mathrm{H}-14) ; 5.27$ (s, 2H, H-8); 2.20 (s, 3H, H-15). ${ }^{13} \mathrm{C}-\mathrm{NMR}: 178.91$ (C-16); 170.00 (C-1); 161.57 (d, $\left.J_{(\mathrm{F}-\mathrm{C})}=241.0 \mathrm{~Hz}, \mathrm{C}-19\right) ; 156.05$ (C-9); 139.48 (C-3); 135.81 (C-2); 133.16 (C-12); 129.60 (C-17); 130.98 (C-5); 130.19 (C-21); 129.71 (C-11, C-13); 128.43 (C-7); 128.27 (C-4); 127.64 (C-6); 120.05 (C-22); 114.49 (C-10, C-14); 112.80 (d, $J_{(\mathrm{F}-\mathrm{C})}=21.2$ $\mathrm{Hz}, \mathrm{C}-20) ; 110.95$ (d, $\left.J_{(\mathrm{F}-\mathrm{C})}=25.7 \mathrm{~Hz}, \mathrm{C}-18\right) ; 67.40$ (C-8); $19.96(\mathrm{C}-15)$. FT-IR $\left(v \mathrm{~cm}^{-1}\right)$ : 3345w; $3129 \mathrm{~m} ; 2921 \mathrm{w} ; 2857 \mathrm{w} ; 1675 \mathrm{~m} ; 1601 \mathrm{~m} ; 1551 \mathrm{~s} ; 1504 \mathrm{vs} ; 1445 \mathrm{~s} ; 1380 \mathrm{w} ; 1331 \mathrm{~m} ; 1302 \mathrm{~m} ; 1283 \mathrm{~m}$; $1271 \mathrm{~m} ; 1256 \mathrm{~m} ; 1227 \mathrm{vs} ; 1176 \mathrm{~m} ; 1140 \mathrm{~s} ; 1056 \mathrm{w} ; 1024 \mathrm{~m} ; 985 \mathrm{w} ; 958 \mathrm{w} ; 899 \mathrm{w} ; 860 \mathrm{w} ; 829 \mathrm{w} ; 800 \mathrm{w} ;$ 781w; 727m; 669m; 605w; 555w; 512w. Anal. Calcd for $\mathrm{C}_{22} \mathrm{H}_{19} \mathrm{FN}_{2} \mathrm{O}_{2} \mathrm{~S}$ (394.46): C, 66.99; H, 4.85; N, 7.10; S, 8.13\%; Found: C, 67.33; H, 4.72; N, 7.03; S 8.15\%.

2-((4-Methylphenoxy)methyl)-N-(2,3,4-trifluorophenylcarbamothioyl)benzamide (1k); yield 71\%, mp 111.2-112.3 ${ }^{\circ} \mathrm{C} .{ }^{1} \mathrm{H}-\mathrm{NMR}: 12.13$ (br s, $1 \mathrm{H}, \mathrm{NH}$ ); 12.10 (br s, $1 \mathrm{H}, \mathrm{NH}$ ); 7.63 (bd, $J=7.4 \mathrm{~Hz}, 1 \mathrm{H}$, H-7); $7.62-7.54$ (m, 3H, H-4, H-5, H-22); 7.47 (td, $J=1.4 \mathrm{~Hz}, J=7.5 \mathrm{~Hz}, 1 \mathrm{H}, \mathrm{H}-6$ ); 7.36 (ddd, $\left.J_{(\mathrm{F}-20-\mathrm{H}-21)}=9.5 \mathrm{~Hz},{ }^{3} J_{(\mathrm{H}-22-\mathrm{H}-21)}=8.2 \mathrm{~Hz},{ }^{4} J_{(\mathrm{H}-22-\mathrm{H}-21)}=2.3 \mathrm{~Hz}, 1 \mathrm{H}, \mathrm{H}-21\right) ; 7.04(\mathrm{~d}, J=8.6 \mathrm{~Hz}, 2 \mathrm{H}, \mathrm{H}-11$, H-13); 6.86 (d, $J=8.6 \mathrm{~Hz}, 2 \mathrm{H}, \mathrm{H}-10, \mathrm{H}-14) ; 5.27$ (s, 2H, H-8); 2.22 (s, 3H, H-15). ${ }^{13} \mathrm{C}-\mathrm{NMR}: 179.89$ (C-16); 170.23 (C-1); 156.01 (C-9); 135.74 (C-2); 135.49 (C-12); 135.75 (C-3); 133.11; 131.05 (C-5); 130.40 (C-19); 129.66 (C-11, C-13); 129.58; 129.32; 129.31 (C-7); 128.48 (C-4); 128.27 (C-22); 127.87; 127.77 (C-6); 114.44 (C-10, C-14); 67.51 (C-8); 19.99 (C-15). FT-IR ( $\left.\mathrm{c} \mathrm{cm}^{-1}\right)$ : 3243w; 2990w; 2927w; $1680 \mathrm{~m} ; 1620 \mathrm{~m} ; 1578 \mathrm{~m} ; 1511 \mathrm{vs} ; 1477 \mathrm{~m} ; 1445 \mathrm{~m} ; 1385 \mathrm{w} ; 1324 \mathrm{~s} ; 1237 \mathrm{~s} ; 1191 \mathrm{~s} ; 1178 \mathrm{~m} ; 1152 \mathrm{~m} ; 1054 \mathrm{w} ;$ $1035 \mathrm{~m} ; 1005 \mathrm{~m} ; 902 \mathrm{w} ; 857 \mathrm{w} ; 804 \mathrm{~m} ; 783 \mathrm{w} ; 758 \mathrm{w} ; 741 \mathrm{~m} ; 673 \mathrm{~m} ; 604 \mathrm{w}$. Anal. Calcd for $\mathrm{C}_{22} \mathrm{H}_{17} \mathrm{~F}_{3} \mathrm{~N}_{2} \mathrm{O}_{2} \mathrm{~S}$ (430.44): C, 61.39; H, 3.98; N, 6.51; S, 7.45\%; Found: C, 61.57; H, 4.08; N, 6.59; S 7.48\%. 
2-((4-Methylphenoxy)methyl)-N-(2,4,5-trifluorophenylcarbamothioyl)benzamide (11); yield 81\%, mp 137.3-138.6 ${ }^{\circ} \mathrm{C} .{ }^{1} \mathrm{H}-\mathrm{NMR}: 12.31$ (br s, $1 \mathrm{H}, \mathrm{NH}$ ); 12.11 (br s, $\left.1 \mathrm{H}, \mathrm{NH}\right) ; 8.08$ (m, 1H, H-22); 7.70 (td, $\left.{ }^{3} J_{(\mathrm{F}-18,20-\mathrm{H}-19)}=10.6 \mathrm{~Hz},{ }^{4} J_{(\mathrm{F}-21-\mathrm{H}-19)}=7.4 \mathrm{~Hz}, 1 \mathrm{H}, \mathrm{H}-19\right) ; 7.62$ (bd, $\left.J=7.4 \mathrm{~Hz}, 1 \mathrm{H}, \mathrm{H}-7\right) ; 7.58$ (dd, $J=1.6$ $\mathrm{Hz}, J=7.4 \mathrm{~Hz}, 1 \mathrm{H}, \mathrm{H}-4) ; 7.55$ (td, $J=1.4 \mathrm{~Hz}, J=7.4 \mathrm{~Hz}, 1 \mathrm{H}, \mathrm{H}-5) ; 7.46$ (td, $J=1.4 \mathrm{~Hz}, J=7.5 \mathrm{~Hz}$, 1H, H-6); 7.05 (d, $J=8.6$ Hz, 2H, H-11, H-13); 6.87 (d, J=8.6 Hz, 2H, H-10, H-14); 5.26 (s, 2H, H8); 2.21 (s, 3H, H-15). The resonance signal of $\mathrm{H}-22$ is a multiplet, because it is coupled with all three fluorine atoms with different constants, and the ratio between the diference of chemical shifts and coupling constant value is less than $5(\Delta v / J) .{ }^{13} \mathrm{C}-\mathrm{NMR}: 180.38$ (C-16); 170.27 (C-1); 156.01 $(\mathrm{C}-9) ; 152.04\left(\mathrm{ddd}, J_{(\mathrm{F}-18-\mathrm{C}-18)}=243.8 \mathrm{~Hz}, J_{(\mathrm{F}-20-\mathrm{C}-18)}=7.4 \mathrm{~Hz}, J_{(\mathrm{F}-21-\mathrm{C}-18)}=2.2 \mathrm{~Hz}, \mathrm{C}-18\right) ; 148.02(\mathrm{ddd}$, $\left.J_{(\mathrm{F}-20-\mathrm{C}-20)}=248.1 \mathrm{~Hz}, J_{(\mathrm{F}-21-\mathrm{C}-20)}=14.7 \mathrm{~Hz}, J_{(\mathrm{F}-18-\mathrm{C}-20)}=11.8 \mathrm{~Hz}, \mathrm{C}-20\right) ; 145.73\left(\mathrm{ddd}, J_{(\mathrm{F}-21-\mathrm{C}-21)}=241.6 \mathrm{~Hz}\right.$, $\left.{ }^{2} J_{(\mathrm{F}-20-\mathrm{C}-21)}=13.3 \mathrm{~Hz},{ }^{3} J_{(\mathrm{F}-18-\mathrm{C}-21)}=3.7 \mathrm{~Hz}, \mathrm{C}-21\right) ; 135.84(\mathrm{C}-3) ; 133.02(\mathrm{C}-2) ; 131.08$ (C-5); 129.71 (C11, C-13); 129.64 (C-12); 128.51 (C-7); 128.40 (C-4); 127.71 (C-6); 122.83 (m, C-17); 115.25 (dd, $\left.{ }^{2} J_{(\mathrm{F}-21-\mathrm{C}-22)}=22.0 \mathrm{~Hz},{ }^{3} J_{(\mathrm{F}-20-\mathrm{C}-22)}=13.2 \mathrm{~Hz}, \mathrm{C}-22\right) ; 114.55(\mathrm{C}-10, \mathrm{C}-14) ; 105.93\left(\mathrm{dd},{ }^{2} J_{(\mathrm{F}-18-\mathrm{C}-19)}=21.9 \mathrm{~Hz}\right.$, $\left.{ }^{2} J_{(\mathrm{F}-20-\mathrm{C}-19)}=26.3 \mathrm{~Hz}, \mathrm{C}-19\right) ; 67.47(\mathrm{C}-8) ; 19.96(\mathrm{C}-15)$. FT-IR $\left(v^{-1} \mathrm{~cm}^{-1}\right): 3249 \mathrm{~m} ; 3075 \mathrm{w} ; 2919 \mathrm{~m} ; 1676 \mathrm{~m}$; $1601 \mathrm{w} ; 1563 \mathrm{vs} ; 1508 \mathrm{vs} ; 1438 \mathrm{~s} ; 1384 \mathrm{w} ; 1316 \mathrm{~s} ; 1235 \mathrm{~s} ; 1215 \mathrm{vs} ; 1204 \mathrm{~s} ; 1155 \mathrm{~s} ; 1102 \mathrm{~m} ; 1054 \mathrm{~m} ; 1036 \mathrm{~m}$; 942w; 868m; 829w; 804w; 786w; 748w; 703m; 677m; 635w; 585w. Anal. Calcd for $\mathrm{C}_{22} \mathrm{H}_{17} \mathrm{~F}_{3} \mathrm{~N}_{2} \mathrm{O}_{2} \mathrm{~S}$ (430.44): C, 61.39; H, 3.98; N, 6.51; S, 7.45\%; Found: C, 61.71; H, 3.82; N, 6.58; S 7.47\%.

2-((4-Methylphenoxy)methyl)-N-(2,4,6-trifluorophenylcarbamothioyl)benzamide (1m); yield 82\%, mp 137.3-138.6 ${ }^{\circ} \mathrm{C} .{ }^{1} \mathrm{H}-\mathrm{NMR}: 12.10$ (br s, $1 \mathrm{H}, \mathrm{NH}$ ); 11.56 (br s, $\left.1 \mathrm{H}, \mathrm{NH}\right) ; 7.64$ (bd, $J=7.4 \mathrm{~Hz}, 1 \mathrm{H}$, $\mathrm{H}-7$ ); 7.58 (dd, $J=1.6 \mathrm{~Hz}, J=7.4 \mathrm{~Hz}, 1 \mathrm{H}, \mathrm{H}-4) ; 7.55$ (td, $J=1.4 \mathrm{~Hz}, J=7.4 \mathrm{~Hz}, 1 \mathrm{H}, \mathrm{H}-5$ ); 7.46 (td, $J=1.4 \mathrm{~Hz}, J=7.5 \mathrm{~Hz}, 1 \mathrm{H}, \mathrm{H}-6) ; 7.30$ (m, 2H, H-19, H-21, syst. AA'BB'C); 7.07 (d, $J=8.6 \mathrm{~Hz}, 2 \mathrm{H}$, H-11, H-13); 6.88 (d, $J=8.6 \mathrm{~Hz}, 2 \mathrm{H}, \mathrm{H}-10, \mathrm{H}-14) ; 5.26$ (s, 2H, H-8); 2.22 (s, 3H, H-15). ${ }^{13} \mathrm{C}-\mathrm{NMR}$ : $182.69(\mathrm{C}-16) ; 170.26(\mathrm{C}-1) ; 160.08\left(\mathrm{dt}, J_{(\mathrm{F}-\mathrm{C}-20)}=248.2 \mathrm{~Hz},{ }^{3} J_{(\mathrm{F}-18,22-\mathrm{C}-20)}=15.0 \mathrm{~Hz}, \mathrm{C}-20\right) ; 159.92$ $\left(\mathrm{ddd}, J_{(\mathrm{F}-18-\mathrm{C}-18)}=257.8 \mathrm{~Hz}, J_{(\mathrm{F}-20-\mathrm{C}-18)}=6.6 \mathrm{~Hz}, J_{(\mathrm{F}-22-\mathrm{C}-18)}=12.3 \mathrm{~Hz}, \mathrm{C}-18, \mathrm{C}-22\right) ; 156.50(\mathrm{C}-9) ; 136.39$ (C-3); 133.54 (C-2); 130.22 (C-12); 131.62 (C-5); 130.28 (C-11, C-13); 129.20 (C-7); 129.04 (C-4); 128.29 (C-6); 115.24 (C-10, C-14); 101.36 (t, $\left.J_{(\mathrm{F}-\mathrm{C})}=27.8 \mathrm{~Hz}, \mathrm{C}-19, \mathrm{C}-21\right) ; 68.11$ (C-8); 20.60 (C-15). The C-19 and C-21 signal is a triplet due to their scalar coupling with the orto fluorine atoms. FT-IR $\left(v \mathrm{~cm}^{-1}\right): 3193 \mathrm{~m} ; 3071 \mathrm{w} ; 2922 \mathrm{w} ; 1673 \mathrm{~s} ; 1644 \mathrm{w} ; 1603 \mathrm{w} ; 1586 \mathrm{w} ; 1527 \mathrm{vs} ; 1509 \mathrm{vs} ; 1447 \mathrm{~s} ; 1382 \mathrm{w}$; $1341 \mathrm{~m} ; 1289 \mathrm{w} ; 1243 \mathrm{~s} ; 1229 \mathrm{~s} ; 1174 \mathrm{vs} ; 1122 \mathrm{~s} ; 1037 \mathrm{~s} ; 998 \mathrm{w} ; 853 \mathrm{~m} ; 810 \mathrm{~m} ; 787 \mathrm{w} ; 753 \mathrm{~m} ; 733 \mathrm{~m} ; 672 \mathrm{~m}$; 509w. Anal. Calcd for $\mathrm{C}_{22} \mathrm{H}_{17} \mathrm{~F}_{3} \mathrm{~N}_{2} \mathrm{O}_{2} \mathrm{~S}$ (430.44): C, 61.39; H, 3.98; N, 6.51; S, 7.45\%; Found: C, $61.74 ; \mathrm{H}, 3.79 ; \mathrm{N}, 6.48 ; \mathrm{S} 7.37 \%$.

\subsection{Biological Assays}

3.2.1. Assessment of the Antimicrobial and Anti-Pathogenic Activity of the Newly Synthesized Compounds

The in vitro qualitative screening of the antimicrobial activity was carried out by an adapted agardisk diffusion technique using a bacterial suspension of 0.5 McFarland obtained from 24 hour cultures $[33,34]$. The antimicrobial activities of the newly synthesized compounds were determined against ATCC reference microbial strains, i.e., S. aureus ATCC 25923, Enterococcus faecalis ATCC 29212, E. coli ATCC 25922, as well as clinical strains, recently isolated from different clinical specimens, i.e., 
S. aureus 1694, Salmonella sp. 9246, K. pneumoniae 1771, P. aeruginosa 1671, C. albicans 128 and Aspergillus niger IC 13534. The microbial strains identification was confirmed by aid of VITEK I automatic system. VITEK cards for identification and susceptibility testing (GNS-522) were inoculated and incubated according to the manufacturer's recommendations. The results were interpreted by using software version AMS R09.1. The compounds were solubilized in dimethyl sulfoxide to a final concentration of $10 \mathrm{mg} / \mathrm{mL}$. The obtained solutions were further sterilized by filtration. A volume of $10 \mu \mathrm{L}$ of each tested compounds solution was distributed directly on the solid medium previously seeded with the microbial inocula. The inoculated plates were incubated for $24 \mathrm{hrs}$ at $37{ }^{\circ} \mathrm{C}$. Antimicrobial activity was assessed by measuring the growth inhibition zones diameters expressed in $\mathrm{mm}[36,37]$. The quantitative assay of the minimal inhibitory concentration (MIC, $\mu \mathrm{g} / \mathrm{mL}$ ) was based on liquid medium two-fold microdilutions and performed in 96 multi-well plates $[34,35]$. In this purpose, serial binary dilutions of the tested compounds (ranging between 1,000 and $0.975 \mu \mathrm{g} / \mathrm{mL}$ ) were performed in a $200 \mu \mathrm{L}$ volume of nutrient broth/YPG and each well was seeded with $20 \mu \mathrm{L}$ microbial inocula of $0.5 \mathrm{McFarland}$ density. The plates were incubated for 24 hours at 37 ${ }^{\circ} \mathrm{C}$ for bacterial strains, respectively for 48 hours at $28{ }^{\circ} \mathrm{C}$ for fungal strains and MICs were read as the last concentration of compound which inhibited the microbial growth.

\subsubsection{Study of the Influence of the Selected Compounds on the Ability of P. aeruginosa, S. aureus} and K. pneumoniae to Colonize the Inert Substratum and Form Biofilms

The anti-biofilm activity of the tested compounds was tested by the microtiter method. For this purpose, the microbial strains have been grown in the presence of two-fold serial dilutions of the tested compounds performed in liquid nutrient broth/YPG, distributed in 96-well plates and incubated for 24 hours at $37{ }^{\circ} \mathrm{C}$ for bacterial strains, respectively for 48 hours at $28{ }^{\circ} \mathrm{C}$ for fungal strains. At the end of the incubation period, the plastic wells were emptied, washed three times with phosphate buffered saline (PBS), fixed with cold methanol and stained with $1 \%$ violet crystal solution for 30 minutes. The biofilm formed on plastic wells was resuspended in 30\% acetic acid. The intensity of the colored suspensions was assessed by measuring the absorbance at $490 \mathrm{~nm}$. The last concentration of the tested compound that inhibited the development of microbial biofilm on the plastic wells was considered the minimum inhibitory concentration of the biofilm development and was also expressed in $\mu \mathrm{g} / \mathrm{mL}$ $[36,37]$.

\section{Conclusions}

New 2-((4-methylphenoxy)methyl)- $N$-(arylcarbamothioyl)benzamides were prepared from 2-(4methylphenoxymethyl)benzoyl chloride via isothiocyanate formation, followed by treatment with various substituted amines. Our results showed that some of the newly synthesized thiourea derivatives carrying aryl groups substituted with one iodine, bromide, fluorine or with two or three chloride atoms could be used for the further development of novel antimicrobial agents with anti-biofilm properties. 


\section{Acknowledgments}

The present study was supported by the financial aid of the following research projects: PN2 41043/2007, PN2 42150/2008 and Capabilities/ Module III -Romanian- Turkey bilateral project no. 378/ 2010).

\section{References and Notes}

1. Struga, M.; Rosolowski, S.; Kossakowski, J.; Stefanska, J. Synthesis and Microbiological Activity of Thiourea Derivatives of Azatricyclo[5.2.2.0 $\left.0^{2,6}\right]$ undec-8-ene-3,5-dione. Arch. Pharm. Res. 2010, $33,47-54$.

2. Doğruer, D.; Urlu, Ş.; Önkol, T.; Özçelik, B.; Şahin, M.F. Synthesis of some pyridazine derivatives carryng urea, thiourea, and sulfonamide moieties and their antimicrobial activity. Turk. J. Chem. 2010, 34, 57-65.

3. Saeed, A.; Abbas, N.; Rafique, H.; Rashid, S.; Hameed, A. Synthesis, characterization and antibacterial activity of some 1-aroyl-3-aryl-thioureas. Chemistry 2009, 18, 152-158.

4. Saeed, A.; Rafique, H.; Hammed, A.; Rasheed, S. Synthesis and antibacterial activity of some new 1-aroyl-3-(substituted-2-benzothiazolyl)thioureas. Pharmaceut. Chem. J. 2008, 42, 191-195.

5. Cunha, S.; Macedo, F.C., Jr.; Costa, G.A.N.; Rodrigues, M.T., Jr.; Verde, R.B.V.; de Souza Neta, L.C.; Vencato, I.; Lariucci, C.; Sa', F.P. Antimicrobial activity and structural study of disubstituted thiourea derivatives. Monatsh. Chem. Chem. Mon. 2007, 138, 511-516.

6. Saeed, S.; Rashid, N.; Jones, P.G.; Hussain, R.; Bhatti, M.H. Synthesis, spectroscopic characterization, crystal structure and antifungal activity of thiourea derivatives containing a thiazole moiety. Cent. Eur. J. Chem. 2010, 8, 550-558.

7. Saeed, A.; Shaheen, U.; Hameed, A.; Haider Naqvi, S.Z. Synthesis, characterization and antimicrobial activity of some new 1-(fluorobenzoyl)-3-(fluorophenyl)thioureas. J. Fluor. Chem. 2009, 130, 1028-1034.

8. Karaku, S.; Rollas, S.; Synthesis and antituberculosis activity of new N-phenyl-N'-[4-(5-alkyl/ arylamino-1,3,4-thiadiazole-2-yl)phenyl]thioureas. Farmaco 2002, 57, 577-581.

9. Liav, A.; Angala, S.K.; Brennan, P.J.; Jackson, M. N-D-Aldopentofuranosyl-N'-[p(isoamyloxy)phenyl]thiourea derivatives: Potential anti-TB therapeutic agents. Bioorg. Med. Chem. Lett. 2008, 18, 2649-2651.

10. Dharmarajan, S.; Perumal, Y.; Murugesan, D.; Rathinasababathy, T. Antimycobacterial activity of novel 1-(5-cyclobutyl-1,3-oxazol-2-yl)-3(sub)phenyl/ pyridyl thiourea compounds iendowed with high activity toward multidrug-resistant Mycobacterium tuberculosis. J. Antimicrob. Chemother. 2007, 59, 1194-1196.

11. Walchshofer, N.; Delabre-Defayolle, I.; Paris, J.; Petavy, A.F. In vivo morphological damage induced by a new benzimidazole prodrug in Echinococcus multilocularis metacestodes. J. Pharm. Sci. 1990, 79, 606-608.

12. Mishra, A.; Srivastava, K.; Tripathi, R.; Puri, S.K.; Batra, S. Search for new pharmacophores for antimalarial activity. Part III: synthesis and bioevaluation of new 6-thioureido-4anilinoquinazolines. Eur. J. Med. Chem. 2009, 44, 4404-4412. 
13. Çikla, P.; Küçükgüzel, Ş.G.; Küçükgüzel, I.; Rollas, S.; De Clercq, E.; Pannecouque, C.; Andrei, G.; Snoeck, R.; Şahin, F.; Bayrak, Ö.F. Synthesis and evaluation of antiviral, antitubercular and anticancer activities of some novel thioureas derived from 4aminobenzohydrazide hydrazones. Marmara Pharm. J. 2010, 14, 13-20.

14. Park, H.-G.; Choi, J.-Y.; Choi, S.-H.; Park, M.-K.; Lee, J.; Suh, Y.-G.; Cho, H.; Oh, U.; Lee, J.; Kang, S.-U.; Lee, J.; Kim, H.-D.; Park, Y.-H.; Jeong, Y.S.; Choi, J.K.; Jew, S.S. N-4-Substitutedbenzyl-N'-tert-butylbenzyl thioureas as vanilloid receptor ligands: investigation on the role of methanesulfonamido group in antagonistic activity. Bioorg. Med. Chem. Lett. 2004, 14, 787-791.

15. Patel, R.B.; Chikhalia, K.H.; Pannecouque, C.; De Clercq, E. Synthesis of novel PETT Analogues: 3,4-Dimethoxy Phenyl Ethyl-1,3,5-Triazinyl Thiourea Derivatives and their Antibacterial and Anti-HIV Studies. J. Braz. Chem. Soc. 2007, 18, 312-321.

16. Sun, C.; Huang, H.; Feng, M.; Shi, X.; Zhang, X.; Zhou, P. A novel class of potent influenza virus inhibitors: Polysubstituted acylthiourea and its fused heterocycle derivatives Bioorg. Med. Chem. Lett. 2006, 16, 162-166.

17. Kayser, H.; Eilinger, P. Metabolism of diafenthiuron by microsomal oxidation: procide activation and inactivation as mechanisms contributing to selectivity. Pest. Manag. Sci. 2001, 57, 975-980.

18. Paul, A.; Harrington, L.C.; Scott, J.C. Evaluation of novel insecticides for control of the dengue vector, Aedes aegypti. J. Med. Entomol. 2006, 43, 55-60.

19. Ramadas, K.; Suresh, G.; Janarthanan, N.; Masilamani, S. Antifungal activity of 1,3-disubstituted symmetrical and unsymmetrical thioureas. Pestic. Sci. 1998, 52, 145-151.

20. Ke, S.Y.; Xue, S.J. Synthesis and herbicidal activity of $N$-(o-fluorophenoxyacetyl)thioureas derivatives and related fused heterocyclic compounds. ARKIVOC 2006, 63-68.

21. Kumar, S.; Awasthi, V.; Kanwar, J.K. Influence of growth regulators and nitrogenous compounds on in vitro bulblet formation and growth in oriental lily. Hort. Sci. (Prague) 2007, 34, 77-83.

22. Hernández, W.; Spodine, E.; Beyer, L.; Schröder, U.; Richter, R.; Ferreira, J.; Pavani, M. Synthesis, Characterization And Antitumor Activity Of Copper(II) Complexes, $\left[\mathrm{CuL}_{2}\right]\left[\mathrm{HL}^{1-3}=\mathrm{N}, N\right.$-Diethyl-N'(R-Benzoyl)Thiourea (R=H, o-Cl and p-NO $\left.{ }_{2}\right)$ ]. Bioinorg. Chem. Appl. 2005, 3, 299-316.

23. Balotescu M.C.; Limban, C.; Missir, A.V.; Chiriță, I.C.; Nițulescu, G.M. The synthesis and biological activities of some new 2-(4-methoxy-phenoxymethyl)benzoic acid thioureides. Rev. Chim. (Bucharest) 2007, 58, 1064-1068.

24. Limban, C.; Balotescu M.C.; Missir, A.V.; Chiriță, I.C.; Bleotu, C. Antimicrobial activity of some new thioureides derived from 2-(4-chlorophenoxymethyl)benzoic acid thioureides. Molecules 2008, 13, 567-580.

25. Limban, C.; Missir, A.V.; Chirita, I.C.; Neagu, A.F.; Draghici, C., Chifiriuc, M.C. Synthesis and antimicrobial evaluation of some new 2-(4-fluoro-phenoxymethyl)benzoic acid thioureides. Rev. Chim. (Bucharest) 2011, 62, 168-173.

26. Limban, C., Missir, A.V.; Chirita, I.; Nitulescu, G.M.; Caproiu, M.; Israil, A.M. Synthesis and antimicrobial properties of new 2-((4-ethylphenoxy)methyl)benzoylthioureas. Chem. Pap. 2011, 65, 60-69.

27. Drãcea, O.; Babes, C.; Limban, C.; Delcaru, C.; Chifiriuc, M.C.; Israil, A.M.I. Antimicrobial activity of some new of 2-(4-ethyl-phenoximethyl) benzoic acid thioureides against planktonic cells. Roum. Arch. Microbiol. Immunol. 2010, 69, 90-95. 
28. Limban, C.; Missir, A.V.; Chiriţă, I.C.; Bădiceanu, C.D.; Drăghici, C.; Balotescu, M.C.; Stamatoiu, O. New thioureides of 2-(4-methyl-phenoxymethyl)-benzoic and 2-(4-methoxyphenoxymethyl)-benzoic acids with biological activity. Revue Roum. Chim. 2008, 53, 595-602.

29. Yoneyama, H.; Katsumata, R. Antibiotic Resistance in Bacteria and Its Future for Novel Antibiotic Development. Biosci. Biotech. Biochem. 2006, 70, 1060-1075.

30. Mihaescu, G.; Chifiriuc, M.C.; Ditu, L.M. Antibiotics and Antimicrobial Substances; Romanian Academy Press: Bucharest, Romania, 2005.

31. De Kievit, T.R.; Parkins, M.D.; Gillis, R.J.; Srikumar, R.; Ceri, H.; Poole, K. Iglewski, B.H.; Storey D.G. Multidrug Efflux Pumps: Expression Patterns and Contribution to Antibiotic Resistance in Pseudomonas aeruginosa Biofilms. Antimicrob. Agents Chemother. 2001, 45, 1761-1770.

32. Thomas, J.G.; Litton, I.; Rinde, H. Economic impact of biofilms on treatment costs. In Biofilms, Infection and Antimicrobial Therapy; Pace, J.L., Rupp, M., Finch, R.G., Eds.; Taylor \& Francis Group: Boca Raton, FL, USA, 2006; pp. 21-38.

33. Limban, C.; Missir, A.V.; Chiriţă, I.C.; Niţulescu, G.M.; Drăchici, B. Synthesis and characterization of some new 2-methyl-O-acyl-oximino-dibenz[b,e]oxepins. Rev. Chim. (Bucharest) 2007, 58, 224-228.

34. Clinical Laboratory Standards Institute. Performance Standards for Antimicrobial Susceptibility Testing; Eighteenth Informational Supplement M100-S18, Vol. 28 No. 1, Replaces M100-S17, Vol. 76 No. 1 Informational Supplement 2008, CLSI, Wayne, PA, USA.

35. Clinical Laboratory Standards Institute. Reference Method for Broth Dilution Antifungal Susceptibility Testing of Yeasts; Approved Standard- Third Edition 2007, M27-A3 ,Vol. 0 No. 0, Replaces M27-A2 ,Vol. 22 No. 15 CLSI, Wayne, PA, USA.

36. Olar, R.; Badea, M.; Marinescu, D.; Chifiriuc, M.C.; Bleotu, C.; Grecu, M.N.; Iorgulescu, E.M.; Bucur, M.; Lazar, A.; Finaru, A. Prospects for new antimicrobials based on $N, N$ dimethylbiguanide complexes as effective agents on both planktonic and adhered microbial strains. Eur. J. Med. Chem. 2010, 45, 2868-2875.

37. Olar, R.; Badea, M.; Marinescu, D.; Chifiriuc, M.C.; Bleotu, C.; Grecu, M.N.; Iorgulescu, E.M.; Lazar, A. $N, N$-Dimethylbiguanide complexes displaying low cytotoxicity as potential large spectrum antimicrobial agents. Eur. J. Med. Chem. 2010, 45, 3027-3034.

Sample Availability: Samples of the compounds are available from the authors.

(C) 2011 by the authors; licensee MDPI, Basel, Switzerland. This article is an open access article distributed under the terms and conditions of the Creative Commons Attribution license (http://creativecommons.org/licenses/by/3.0/). 